\title{
"NÃO COSTUMO PERDER MEU TEMPO COM ESSE TEMA": reflexões sobre o sexismo cotidiano na fala de um docente
}

\author{
"I DON'T USE TO WAST MY TIME WITH THIS ISSUE": reflections on daily sexism based \\ on a male teacher's statement
}

"NO SUELO PERDER MI TIEMPO CON ESE TEMA": reflexiones sobre el sexismo cotidiano en el habla de un maestro

\author{
Valquiria Gila de Amorim \\ Mestra em Educação pela Universidade Federal da Paraíba (UFPB). \\ João Pessoa, PB - Brasil. \\ valquiriagila@gmail.com \\ Maria Eulina Pessoa de Carvalho \\ Professora Doutora da Universidade Federal da Paraíba (UFPB). \\ João Pessoa, PB - Brasil. \\ mepcarv@terra.com.br \\ maria.eulina@pq.cnpq.br \\ Jeane Félix \\ Professora Doutora da Universidade Federal da Paraíba (UFPB). \\ João Pessoa, PB - Brasil. \\ jeanefelix@gmail.com
}

\begin{abstract}
RESUMO: Este artigo parte de um enunciado de um docente da disciplina de Física, colhido em pesquisa de campo, que denota a naturalização das relações de gênero, para problematizar as práticas sexistas correntes nas relações sociais e escolares. Esse enunciado possibilita refletir sobre alguns dos aspectos dessa naturalização, tais como: sexismo e uso da linguagem sexista, violência de gênero e exclusão das mulheres em carreiras masculinizadas, cuja crítica é importante para promover uma educação para a equidade de gênero. Argumenta-se que quando um/a professor/a desconsidera questões de gênero presentes na escola, perde-se a oportunidade de combater a reprodução da desigualdade de gênero e as violências sofridas por mulheres e homens cotidianamente. Nesse contexto, destacam-se os preconceitos e estereótipos que afastam as alunas das ciências exatas e naturais, que persistem como um dos campos mais masculinizados e excludentes para as mulheres.
\end{abstract}

PALAVRAS-CHAVE: Sexismo. Relações de Gênero. Violência de Gênero. Gendramento das Carreiras.

ABSTRACT: The starting point of this paper is a statement by a male Physics teacher, collected in empirical research, which conveys the naturalization of gender relations, in order to problematize current sexist practices in social and school relations. Such a statement allows reflection on some aspects of that naturalization, such as: sexism and use of sexist language, gender violence, and the exclusion of women from masculine careers, whose critique is important to promote education for gender equity. The paper argues that when a teacher neglects gender issues that are present in school life, an important opportunity is missed to address the reproduction of gender inequality and the daily violence suffered by women and men. In this context, it stresses the prejudices and stereotypes that keep female students away from the natural and exact sciences, a field that remains as one the most masculine and exclusionary for women.

KEYWORDS: Sexism. Gender relations. Gender violence. Gendering of careers. 
RESUMEN: Este articulo parte de un enunciado de un docente de la asignatura de Física, recogido en una investigación de campo, que denota la naturalización de las relaciones de género, para problematizar las prácticas sexistas corrientes en las relaciones sociales y escolares. Esa afirmación posibilita reflexionar sobre algunos de los aspectos de esa naturalización, tales como: el sexismo y el uso del lenguaje sexista, la violencia de género y la exclusión de las mujeres en careras masculinizadas, cuya crítica es importante para promocionar una educación para la equidad de género. Se argumenta que cuando uno/a profesor/a desconsidera cuestiones de género presentes en la escuela, se pierde la oportunidad de combatir la reproducción de la desigualdad de género y las violencias sufridas por mujeres y hombres cotidianamente. En ese contexto, se sobresalen los prejuicios y estereotipos que alejan las alumnas de las ciencias exactas y naturales, que persisten como uno de los campos más masculinizados y excluyentes para las mujeres.

PALABRAS CLAVE: Sexismo. Relaciones de Género. Violencia de Género. Generización de las Carreras. 


\section{1| INTRODUÇÃO}

Neste artigo, analisamos e problematizamos o enunciado de um docente da disciplina de Física do Ensino Médio e Tecnológico de uma instituição pública de ensino superior, localizada no Nordeste do Brasil'. Buscamos visibilizar no enunciado desse docente, a sua percepção sobre as relações de gênero e práticas sexistas, invisibilizadas e naturalizadas, que podem ter implicações no seu exercício docente e na reprodução do gendramento na disciplina de Física, bem como, em outras atividades educativas das quais o referido professor participa. Por gendramento, referimonos ao processo de exclusão de meninas e mulheres da área de ciências exatas tornando-a um campo masculino de conhecimento e de prática científica (CARVALHO; RABAY, 2013). Neste texto, entendemos gênero como a construção social das masculinidades e feminilidades, como um sistema de signos e símbolos atravessados por relações de poder e hierarquia entre homens e mulheres, que organizam as práticas sociais (divisão do trabalho) e a estrutura psicossomática (habitus, identidade) definindo, assim, padrões comportamentais para eles e elas (CARVALHO; ANDRADE; JUNQUEIRA, 2009). Segundo Scott (1988, p. 197), "o gênero é um primeiro modo de dar significado às relações de poder, caracterizando-se pela dominação e exploração" dos homens sobre as mulheres. Sendo uma das formas primárias das relações de poder, o gênero não é uma essência ou uma qualidade intrínseca, mas "é a relação entre categorias de homens e de mulheres, constituídas de forma variada e diferenciada por nação, geração, classe, linhagem, cor e muito mais" (HARAWAY, 1998, p. 28).

A motivação para o enfoque desta temática surgiu a partir de entrevistas realizadas, no ano de 2015, com uma professora e um professor de Física do Ensino Médio e Tecnológico sobre suas experiências e trajetórias na educação básica, superior e profissional (AMORIM; PINTO; CARVALHO, 2016). Mesmo com os avanços conquistados pelas mulheres nos últimos anos, especialmente no campo educacional, a sua representatividade na Física, entre outras ciências duras, continua baixa (AGRELLO; GARG, 2009), sendo a Física considerada de alto prestígio e reconhecida como a mais científica das ciências (SCHIEBINGER, 2001). Ciências "duras" são cosideradas aquelas que implicam pensamento mais abstrato.

Segundo apontam Carvalho e Rabay (2013), em 2011, apenas 18,6\% das matrículas no Bacharelado e $14,2 \%$ na Licenciatura em Física na Universidade Federal da Paraíba (UFPB) eram de mulheres. Em 2015, dados fornecidos pela Coordenação de Física da UFPB mostravam que este número não avançou, correspondendo a $17,67 \%$ de presença feminina em um total de 300 matrículas. No ano de 2016, as mulheres representavam $15 \%$ das matrículas no total de 338 estudantes de graduação: no Bacharelado, o total de estudantes é de 53 , sendo $20,75 \%$ de muIheres; e, na Licenciatura, em um total de 62 estudantes, as mulheres são 16, isto é, $12 \%$. Na Pós-Graduação, os números também são baixos: em 2014, eram apenas 4 mestrandas num corpo discente de 26, e 7 doutorandas num corpo discente de 63; em 2016, são 2 mestrandas para 16 mestrandos, e 12 doutorandas para 64 doutorandos, conforme informações disponíveis na página do Departamento de Física da UFPB. Na docência superior, o quadro de ausência feminina permanece, sendo raríssimas as mulheres: no Departamento de Física na mesma instituição, onde nenhuma mulher ingressou depois de 2000, há apenas 2 professoras efetivas, enquanto o número de homens passou de 27, em 2009, para 30, em 2012, e 32, em 2016. A Pós-Graduação tem 28 docentes, mas apenas duas são mulheres, sendo uma interna e outra visitante.

\footnotetext{
${ }^{1}$ Integra a pesquisa "Relações de gênero em cursos masculinos: engenharias mecânica e civil, física, matemática e ciência da computação" (CARVALHO, 2014).
} 
Portanto, a raridade das mulheres está estabelecida nesse campo e tende a se reproduzir, se não for problematizada, e se não forem adotadas estratégias efetivas e a curto prazo em todo o sistema educacional para mudar essa situação. O conhecimento científico nas ciências chamadas de exatas vai sendo construído de forma quase unilateral por homens e para os homens, permanecendo a reprodução da cultura androcêntrica, em que as mulheres continuam associadas aos estereótipos de feminilidade e avançam timidamente (DÍAZ MARTÍNEZ, 2015).

Segundo as feministas vêm denunciando ao longo da última metade do século $X X$, a sociedade se organiza de forma gendrada e isso perpassa o campo das ciências. Segundo Schiebinger (2001), a ciência não é neutra em relação às questões de gênero e a exclusão feminina na carreira científica acontece pelos seguintes fatores: estrutura social masculina, divergências entre as esferas pública e privada, e dissociação do saber considerado científico do senso comum. A autora ainda argumenta que "a ciência exigiu, e vai continuar a exigir, profundas mudanças estruturais na cultura, métodos e conteúdos da ciência" para que as mulheres sejam vistas e reconhecidas nesse campo (SCHIEBINGER, 2001, p. 37).

Recentemente, um levantamento realizado por Amorim e Carvalho (2015), sobre as produções acadêmicas sobre mulheres na Física no período de 2006 a 2014, revelou apenas cinco trabalhos sobre as questões de gênero na Física (KELLER, 2006; LIMA, 2008, 2013; AGRELLO; GARG, 2009; CARTAXO, 2012), entre eles, quatro com o sujeito mulher e um sobre homens e mulheres nesta área. Numa nova busca, foram encontrados apenas uma dissertação (LIMA JÚNIOR, 2009) e um artigo (TEIXEIRA; FREITAS, 2014) a mais.

A falta de estudos sobre as mulheres na carreira científica em Física e outras ciências duras "mostra uma grave falta de estudos fundamentados, crítica e teoricamente, sobre gênero e ensino das ciências" (DANIELSSON, 2012, p. 25), decorrente de uma lacuna histórica de centenas de anos de exclusão das mulheres das ciências.

O resultado de uma pesquisa realizada sobre as trajetórias de um homem e uma mulher docentes da disciplina de Física indica que as vivências de ambos em um campo majoritariamente masculino, se apresentam de formas bastante distintas. Entre vários preconceitos e discriminações de gênero, destaca-se a falta de credibilidade durante a vida acadêmica e profissional vivenciada exclusivamente pela professora, corroborando os achados de Lombardi (2008) sobre as dificuldades de inserção das mulheres nos cursos e áreas tecnológicas, também maculinos. Já o conteúdo da entrevista do professor chama atenção pela ausência dessas vivências, naturalização das questões de gênero e maior facilidade de inclusão no campo (AMORIM; PINTO; CARVALHO, 2016).

Em geral, a naturalização e a invisibilidade das questões de gênero nas relações sociais acarretam violências, sejam físicas ou verbais, sofridas pelas mulheres, em diversos espaços e situações. Contudo, a violência simbólica, decorrente do poder simbólico, é uma violência frequentemente imperceptível, vista como banal, natural, "violência doce e quase sempre invisível" (BOURDIEU, 2002, p. 47). Ela pode ocorrer em diversos espaços, na universidade, entre pessoas de alto nível de escolaridade, no contexto da hierarquização e legitimação do saber, passando por brincadeira, piada, falta de reconhecimento e de credibilidade, além de desqualificação de coisas feitas pelas mulheres. Essas formas de violência simbólica, geralmente, não são reconhecidas como sexismo sistêmico institucionalizado (HOOKS, 2000).

A explicação para a persistência e reprodução da dominação de gênero, dominação masculina, segundo Bourdieu (2002), se situa na ordem simbólica androcêntrica (centrada em normas e valores masculinos) e no corpo. A dominação se inscreve em habitus (dominante ou dominado) que são, para o autor, "sistemas de esquemas de percepção, de pensamento e de ação" (BOURDIEU, 2002, p. 17), uma estrutura cognitiva que, de forma objetiva e subjetiva, se constitui no processo de socialização em meio à histórica divisão social e sexual do trabalho. O habitus é fruto de 
"um longo trabalho coletivo de socialização do biológico e de biologização do social" (BOURDIEU, 2002, p. 9), realizado por meio de vários agentes e instituições que, de forma explicita ou implícita, contribuem para fortalecer o processo de dominação de gênero (junto com outros marcadores sociais como de classe e de raça/etnia): a família, a igreja, a escola, os meios de comunicação e o estado. Consequentemente, as pessoas nem sempre se dão conta das relações de dominação implícitas nos corpos, discursos, interações e práticas cotidianas.

Assim, neste artigo, problematizamos o discurso de um docente do sexo masculino da disciplina de Física do Ensino Médio e Tecnológico, que denota a falta de empatia quanto à problemática das relações de gênero e práticas sexistas existentes nos espaços educacionais e sociais, que favorecem a reprodução do gendramento nas disciplinas de ciências exatas e, especificamente, na Física. Com isso, pretendemos ilustrare, ao mesmo tempo, refletir acerca de como os processos de gendramento podem operar no cotidiano de instituições educativas por meio de práticas sexistas naturalizadas.

\section{2 | SITUANDO O DISCURSO MOTE DA ANÁLISE}

Este texto se desdobra do conjunto de materiais empíricos, produzidos pela pesquisa "Relações de gênero em cursos masculinos: engenharias mecânica e civil, física, matemática e ciência da computação" (CARVALHO, 2014). No recorte feito aqui, utilizamos um excerto de entrevista online realizada de modo assíncrono, em 2015, com um docente do sexo masculino da disciplina de Física do Ensino Médio e Tecnológico de uma instituição pública em uma capital nordestina, 31 anos, Doutor em Engenharia Mecânica, uma das mais masculinas entre as engenharias (AMORIM; PINTO; CARVALHO, 2016). A entrevista online assíncrona é aquela em que o/a pesquisador/a envia as perguntas aos/às participantes e eles/elas enviam suas respostas depois de algum tempo, não sendo necessário que ambos estejam online. Neste caso, "a espontaneidade da troca verbal é substituída pela reflexividade das trocas escritas” (FLICK, 2009, p. 243).

Assim, após um contato presencial, o docente foi convidado a participar da pesquisa, tendo os demais contatos ocorridos de modo virtual. Na ocasião, ele foi devidamente informado sobre os objetivos da pesquisa e assinou o Termo de Consentimento Livre e Esclarecido. A entrevista, acerca de sua trajetória e experiências, versou sobre três tópicos principais: educação básica, formação acadêmica e atuação profissional e foi realizada por email e whatsapp, devido à falta de tempo do professor.

$\mathrm{Na}$ análise da entrevista com o professor ficou patente sua indiferença ou ausência de conhecimento quanto às questões de gênero, objeto da investigação, problemática associada à reprodução de uma educação sexista, que, como já foi dito, no exercício da docência, pode contribuir para fortalecer o gendramento das carreiras (CARVALHO; RABAY, 2013) pela ausência de intervenção ou pela omissão. Neste texto, utilizamos apenas um excerto da entrevista realizada com o professor, escolhido como mote para as análises e reflexões deste artigo. Nele, o professor diz:

"Não costumo perder meu tempo com esse tema". Esta foi sua resposta quando questionado se percebia a existência de "brincadeiras" sexistas no ambiente de trabalho, entre colegas ou entre alunos e alunas na escola. Com isso ele quis dizer que não se envolvia com esse assunto; e mais: que esse assunto não importa. $A$ atenção à desigualdade e violência simbólica de gênero $e$ à produção teórica feminista, que enfoca esse tema e busca superar esses problemas, são uma perda de tempo? Por que seriam? Esses problemas não são graves? O tema não é importante? Nesse caso, não é importante para quem?

Com essa abordagem analítica, pretendemos conhecer e visibilizar questões de gênero que atravessam a escola e disciplinas, de uma perspectiva específica, a de um sujeito masculino em um campo dito masculino, numa cultura androcêntrica. 


\section{3 | O SEXISMO E A LINGUAGEM SEXISTA SÃO INOCENTES?}

Sexismo se refere a todos os tipos de preconceito ou discriminação com base no sexo, feminino ou masculino. Geralmente, se chama sexismo o preconceito e a discriminação contra as mulheres, tradicionalmente consideradas "fracas", "medrosas", "incapazes". Poder-se-ia considerar sexismo (contra os homens), o preconceito contra homem chorar, por exemplo, mas, na verdade, quando um homem chora há uma associação com atributos femininos. O sexismo também é ruim para os homens e, por isso, eles precisam se engajar nas reflexões sobre gênero. Por que seria perda de tempo questionar o sexismo na escola, onde ele está presente, por exemplo, na crença de que as mulheres não são suficientemente inteligentes para estudar Física?

Essa resposta do docente expressa vários aspectos que precisam ser refletidos cuidadosamente. A linguagem não é neutra ou inocente, esse sistema, falado e escrito, de imagens ou sinais, reflete crenças e valores, individuais e coletivos, do modo de pensar, sentir e atuar de cada sociedade (MORENO, 1999). Gill (2014) destaca a importância de analisar o contexto social, cultural e político de tudo que é dito ou omitido em um discurso. Frases feitas como: "homem não chora"; "menina tem que ser delicada"; "futebol é jogo de menino"; "boneca é brinquedo de menina"; "homem tem que ser garanhão", "a mulher não pode ser fácil", "homem tem que ser macho", "a mulher precisa de um homem para protegê-la", são utilizadas rotineiramente nas brincadeiras entre os alunos e alunas, por docentes, funcionários escolares, pais, mães, que de forma espontânea ou hostil legitimam o sexismo na escola e na vida social (OLIVEIRA; OLIVEIRA, 2012).

A linguagem sexista, que ainda predomina nas escolas e universidades, pode ser considerada uma expressão de violência simbólica ao invisibilizar (generalizando no masculino) ou desvalorizar as mulheres (referindo-se a elas com termos pejorativos, ou termos que não seriam utilizados para se referir a um homem), veiculando formas de discriminação mais ou menos sutis. Conforme explica Bourdieu (2002, p. 7-8), a violência simbólica se expressa "pelas vias puramente simbólicas da comunicação e do conhecimento, ou, mais precisamente, do desconhecimento, do reconhecimento ou, em última instância, do sentimento."

A dominação masculina (e, consequentemente, a submissão feminina) "só pode ser compreendida se nos mantivermos atentos aos efeitos duradouros que a ordem social exerce sobre as mulheres (e os homens), ou seja, as disposições espontâneas harmonizadas com esta ordem que as impõe" (BOURDIEU, 2002, p. 50). Os/as docentes, em geral, estão inseridos/as neste sistema de dominação masculina e são por ele influenciados/as. Assim, sua visão pode se limitar por crenças, valores e julgamentos familiares, sociais e culturais, impossibilitando distinguir a transmissão de conteúdos, padrões e linguagem, que fortalecem essa superioridade (RIBEIRO; PÁTARO, 2015). Eles e elas nem sempre combatem a linguagem sexista falada no cotidiano escolar e veiculada pelos livros didáticos, a qual por meio de "expressões impregnadas de estereótipos, desigualdades, desrespeito, inverdades científicas, preconceitos, no que diz respeito a mulheres e homens" (LESSA, 2001, p. 65), perpetua o androcentrismo, o sexismo, a misoginia e a violência contra as mulheres nos espaços educacionais.

No Brasil, o movimento para a mudança da linguagem sexista se inicia na década de 1970 , com a manifestação do feminismo brasileiro contra os estereótipos sexuais na escola e nos livros didáticos. Em 1975, a Organização das Nações Unidas (ONU) decretou o Ano Internacional e a Década da Mulher e incorporou pela primeira vez em sua pauta a "educação sexista", logo após os assuntos: "trabalho feminino", "vida reprodutiva" e "violência doméstica" (ROSEMBERG; MOURA; SILVA, 2009, p. 342). Em 1996, o Ministério da Justiça, que então abrigava o ConseIho Nacional dos Direitos da Mulher (CNDM), e o Ministério da Educação (MEC) assinaram um protocolo para combater a discriminação contra as mulheres na educação e nos livros didáticos, fiscalizando a compra e distribuição pelo MEC (ROSEMBERG; MOURA; SILVA, 2009). 
Além disso, em 1998, a Declaração Mundial sobre Educação Superior no Século XXI: Visão e Ação, documento resultante da Conferência Mundial de Educação Superior da Unesco, estabeleceu entre as missões e funções da educação superior, no artigo 4, "o fortalecimento da participação e promoção do acesso das mulheres", incluindo: a eliminação dos estereótipos de gênero e a inclusão da questão do gênero nas disciplinas; o fomento dos estudos da mulher e de gênero como campo específico e estratégico de conhecimento; e a promoção da participação ativa das mulheres na elaboração de políticas e tomada de decisões na educação superior e na sociedade (UNESCO, 1998).

Em 2014, em uma iniciativa localizada, foi lançado um "Manual para uso não Sexista da Linguagem" pela Secretaria de Políticas para Mulheres (SPM) do Governo do Estado do Rio Grande do Sul, mostrando a importância do reconhecimento da mudança do gênero gramatical nos currículos escolares para extinguir os estereótipos de gênero e condutas que contribuem para a desigualdade entre homens e mulheres. A linguagem atual representa os interesses dos homens, não é universal ou inocente, marca negativamente as mulheres; por exemplo, mulher pública: "prostituta", homem público: indivíduo que se consagra à vida pública ou que a ela está ligado; governanta: a que dirige os empregados de uma casa, governante: o que dirige um país ou estado. O manual promove a equidade de gênero na linguagem possibilitando que as pessoas possam visualizar o mundo, em sua multiplicidade (RIO GRANDE DO SUL, 2014).

Assim, ao declarar não ter tempo a perder intervindo nas brincadeiras sexistas, será que o docente tem conhecimento ou ignora toda a produção da teoria feminista, que faz a crítica cultural das relações de gênero? Como se sabe, o ponto de partida dessa crítica é a crença na inferioridade feminina que justificava a exclusão das mulheres das posições de poder e prestígio, na esfera pública, o seu confinamento ao mundo doméstico, assuntos e tarefas considerados de pouca importância, até seu silenciamento pela educação (para a submissão) ou, no extremo, pela violência (PINTO, 2010).

\section{4| VIOLENCIAS E EXCLUSÃO DAS MULHERES}

As mulheres por muito tempo foram consideradas propriedade dos homens que podiam "educá-las" e castigá-las como bem desejavassem. Na sua luta por direitos, só a partir do século XIX encontraram maiores oportunidades educacionais (SILVA, 2010). Em 1879, a Lei Leôncio de Carvalho garantiu às mulheres brasileiras o direito de estudar em instituições de ensino superior. O direito ao voto foi outra grande conquista alcançada em 1932. Bertha Lutz, bióloga e cientista, que estudou no exterior, retornando ao Brasil inicia a luta pelo voto junto às sufragistas brasileiras, feministas da primeira onda (PINTO, 2010).

É somente na década de 1970, que ocorre o acessso massivo das mulheres à educação superior, predominantemente em cursos ligados ao ensino e ao cuidado (BELTRÃO; ALVES, 2009; ROSEMBERG, 2001). Nessa mesma década, segundo Bandeira (2009), iniciam-se avanços "históricos nos processos legislativos, institucionais e jurídicos", organizados e liderados pelo movimento feminista, junto com a sociedade civil, para combater a violência doméstica sofrida pelas mulheres. Buscava-se conscientizar o Estado e a sociedade da necessidade de políticas públicas, com campanhas que denunciavam a violência contra as mulheres - cometida por maridos, companheiros e amantes em nome do amor, da submissão e da honra - que perpertuava uma cultura androcêntrica, sexista, misógina, que ainda hoje vitimiza milhões de mulheres (BANDEIRA, 2009).

Segundo o Mapa da Violência de 2015, baseado no Sistema de Informações de Mortalidade (SIM), é alarmante o crescimento da violência contra a mulher no Brasil. Todos os dias 13 mulheres são mortas só pelo fato de serem mulheres (WAISELFISZ, 2015b). Entre 1980 e 2013, morreu 
um total de 106.093 mulheres, vítimas de homicídio. De fato, o número de vítimas passou de 1.353 mulheres em 1980, para 4.762 em 2013, um aumento de 252\%. Alerta-se que a taxa que, em 1980, era de 2,3 vítimas por 100 mil, passa para 4,8 em 2013, um aumento de 111,1\%. Em 2013, as capitais Vitória, João Pessoa e Fortaleza tiveram taxa acima de 10 homicídios por 100 mil mulheres. Por outro lado, São Paulo e Rio de Janeiro foram as capitais com as menores taxas (WAISELFISZ, 2015b).

Em 2006, foi sancionada a Lei $n^{0} 11.340$, conhecida como Lei Maria da Penha, com a finalidade de promover o rigor das punições para os agressores das mulheres vítimas de violência, alterando o Código Penal. Isso só foi possível depois que Maria da Penha Maia Fernandes, que ficou paraplégica devido à violência cometida pelo marido, em 1983, apelou à Comissão Interamericana de Direitos Humanos da OEA, que condenou o Brasil por não dispor de mecanismos suficientes e eficientes para coibir a prática de violência doméstica contra a mulher. A partir daí, a problemática saiu do âmbito privado e passou a ser responsabilidade do Estado aplicar a lei (BANDEIRA, 2009).

De acordo com a Organização das Nações Unidas (ONU), a publicação da Lei Maria da Penha posicionou o país na frente, mundialmente, ao difundir a lei largamente, de forma que apenas $2 \%$ da população não tinha conhecimento dela. O "Ligue 180" teve um aumento de $1.600 \% \mathrm{em}$ chamadas registradas, 3 milhões de telefonemas recebidos e aumento de $700 \%$ nas denúncias de violência entre 2006 e 2012, demonstrando uma queda nas taxas de homicídio de 2,6\% para 1,7\% ao ano no período 2006-2013 (WAISELFISZ, 2015b).

A violência não se restringe às mulheres. O Mapa da Violência da Juventude (WAISELFISZ, 2015a, p. 73) mostra "enorme concentração de mortalidade nas idades jovens, com pico nos 19 anos de idade, quando os óbitos por arma de fogo atingem a impressionante marca de 62,9 mortes por 100 mil jovens." Destaca-se que a proporção de vítimas do sexo masculino é extremamente elevada: 95\%. A Paraíba encontra-se nas piores posições em relação à média nacional quanto à taxa de óbito masculino por arma de fogo: $63 \%$ para $42 \%$, enquanto a taxa de óbito feminino por arma de fogo nesse estado é 4,9\% em relação a 2,6\%, que é a média nacional. A violência masculina afeta também os homens e essa problemática deve ser estudada e combatido da perspectiva de gênero, porquanto interessa a ambos os sexos (CARVALHO, 2012).

Em 2014, o Brasil ficou em $75^{\circ}$ lugar no Índice de Desenvolvimento Humano e em $85^{\circ}$ no Índice de Desigualdade de Gênero entre os 188 paises pesquisados pelo Programa das Nações Unidas para o Desenvolvimento $(2014,2015)$. Na política, o país continuava ocupando o $121^{\circ}$ lugar no ranking de participação das mulheres em 2015, após 83 anos de conquista do voto feminino. Elas ocupam pouco mais de $10 \%$ dos assentos no Congresso Nacional, apesar do cumprimento da Lei de Cotas (30\%) que completou 20 anos desde a sua primeira redação em 1995 (SABINO; LIMA, 2015).

Similarmente, as políticas e práticas de equidade de gênero na educação básica e superior são incipientes para garantir o acesso e sucesso das mulheres em campos masculinos no Brasil, apesar dos três Planos Nacionais de Políticas para as Mulheres (PNPM) (BRASIL, 2004, 2008, 2013) apontarem a importância de sua participação na educação científica e tecnológica e no trabalho nessas áreas para reduzir as desigualdades de gênero nas carreiras e profissões (PINTO; AMORIM; CARVALHO, 2016). Infelizmente, a versão aprovada do Plano Nacional de Educação (PNE): 2014-2024, excluiu a ênfase na promoção da "igualdade racial, regional, de gênero e de orientação sexual", substituída por "erradicação de todas as formas de discriminação" (BRASIL, 2014, p. 22), diluindo e invisibilizando as especificidades das relações de desigualdade em uma formulação genérica. 


\section{5| EDUCAÇÃO PARA A EQUIDADE DE GÊNERO}

É possível e desejável superar esses problemas sociais, políticos e educacionais de exclusão, segregação e violência que afetam as mulheres. Nessa direção, em 2014, a ONU Mulheres lançou a campanha ElesporElas (HeforShe), com o objetivo de engajar homens e meninos na luta para eliminar todos os tipos de discriminação e violência contra as mulheres e meninas.

Os princípios da campanha são: atenção, argumentação e ação. A atenção envolve educação, sensibilização e conscientização dos homens para que se identifiquem com a bandeira da igualdade de gênero e assumam um papel ativo na sua promoção. A argumentação dirige-se ao envolvimento de homens e meninos em políticas e ações de empoderamento econômico das mulheres, fim da violência contra as mulheres, governança e liderança, paz e segurança. A ação visa captar recursos e outras ações de mobilização social de indivíduos, governos, organizações não governamentais, agências das Nações Unidas, universidades e empresas.

Nessa campanha, a ONU enfatiza a importância da participação masculina no esforço para a equidade de gênero, que não é uma questão apenas das mulheres, pois beneficia toda a sociedade em todos os âmbitos. Ao mesmo tempo, incentiva o empoderamento das mulheres, compreendido como um dispositivo em que as pessoas "tomam controle de seus próprios assuntos, de sua própria vida, de seu destino, tomam consciência de sua habilidade e competência para produzir, criar e gerir" (SILVA, 2000, p. 22), essencial para sucesso e sobrevivência na vida.

É preciso acreditar amplamente que a problemática da desigualdade de gênero não é natural, inerente à ordem das coisas (ou à ordem divina), imutável. Trata-se de uma estrutura de arranjos das relações de poder e sociais: "os dominados, aplicam categorias construídas do ponto de vista dos dominantes às relações de dominação" que, historicamente, vêm reproduzindo a divisão sexual do trabalho baseada na reprodução biológica e social, consequentemente, inferiorizando as mulheres em vários desses arranjos e relações (BOURDIEU, 2002, p. 47).

A crença na naturalidade e imutabilidade da desigualdade de gênero só interessa a quem está numa posição de conforto, usufruindo dos dividendos patriarcais (CONNELL; MESSERSCHMIDT, 2013), homens em posição de privilégio e poder e mulheres (não feministas) associadas e subordinadas a esses homens.

Quando alguém responde como o docente, sujeito desta pesquisa, dizendo que não perde seu tempo com um determinado tema, está deslegitimando tanto o tema, a problemática de gênero, como a interlocutora, uma mulher que o interpela, que está pesquisando o tema, porque este é importante para ela e para as mulheres, como grupo excluído ou subordinado.

Vale lembrar, que na ordem androcêntrica assuntos de homens são mais importantes do que assuntos de mulheres, sendo elas culpadas e responsabilizadas pela sua própria opressão e submissão, efeitos do mecanismo de reprodução da estrutura da dominação masculina que muitas vezes silencia as mulheres (BOURDIEU, 2002).

Nas relações de poder, é crucial observar quem sempre fala e quem só ouve e cala, quem escolhe os temas sobre os quais se deve falar e quem não tem poder de escolha, quem é ouvido $e$ quem não é ouvido. O conceito de empoderamento, caro às feministas, tem entre seus postulados "ganhar voz" e "exercer voz". Como diz a canção Roda Viva de Chico Buarque, "a gente quer ter voz ativa, no nosso destino mandar" (BUARQUE, 1967).

As mulheres têm sido muitas vezes caladas, ignoradas, censuradas, criticadas e excluídas dos lugares de fala do universo masculino, por exemplo, nas ciências. Esse processo de distanciamento dos espaços de poder e afirmação de si começa cedo. Meltzoff (2015) afirma que a partir de seis a oito anos de idade as crianças manifestam estereótipos culturais; as meninas, mesmo obtendo desempenho igual aos meninos, começam a reproduzir frases como: "matemática é coisa 
coisa de menino" ou "matemática não é para mim", que influenciam em sua maneira de pensar sobre os outros e sobre si mesmas. Esse estigma, de forma inconsciente, é incorporado na educação e, na sétima série escolar, as meninas começam a adquirir maior fragilidade na matemática do que os meninos, devido a esse processo de socialização estereotipado (VELHO; LEÓN, 1998).

Deste modo, os homens são mais motivados para as disciplinas como Física, Matemática e Química, consideradas "duras", que implicam mais pensamento abstrato, tempo e dedicação (SCHIEBINGER, 2001), enquanto as mulheres são associadas às disciplinas "moles", as sociais e humanas (TABAK, 2002). Bourdieu (2002, p. 113) alega que professores de disciplinas científicas incentivam menos as mulheres e mais os homens, apoiados também pelos familiares, e ainda afirmam que é "para seu bem", afastando as mulheres das carreiras científicas consideradas masculinas.

No entanto, as poucas mulheres que conseguem adentrar esse campo das ciências encontram o chamado clima frio ou hostil, termo utilizado pela literatura internacional para se referir à falta de receptividade às mulheres em suas tentativas de aproximação e socialização em campos masculinizados (BURGER et al., 2010). Outra denominação, é o "teto de vidro" segundo o qual mesmo as mulheres consideradas e reconhecidas como produtivas encontram barreiras supostamente invisíveis à ascensão em carreiras acadêmicas ou industriais (VELHO; LEÓN, 1998).

Assim, para modificar esse quadro educacional e cultural de desigualdade é fundamental incluir a perspectiva de gênero na formação e produção do conhecimento, em todas as áreas e disciplinas. A transversalidade de gênero, que não se limita à promoção de políticas e práticas afirmativas para a igualdade entre mulheres e homens em todos os setores, precisa ser efetivada nos currículos da educação básica e superior, pois é fundamental para desconstruir as hierarquizações e anular os preconceitos de gênero nas disciplinas, além de oportunizar a inclusão das mulheres em campos masculinizados (MONTANÉ LÓPEZ, 2015). Transversalizar gênero no currículo significa que a perspectiva de gênero atravessa todas as áreas de conhecimento segundo dois eixos: vertical (tema central, disciplinas específicas) e horizontal (como conteúdo de todas as disciplinas) (CARVALHO; RABAY; MORAIS, 2013). Existem problemáticas importantes, a exemplo da violência de gênero, linguagem sexista, segregação de meninos e meninas em certas áreas do conhecimento, que podem ser estudadas em diversas disciplinas.

Além disso, o currículo oculto, que pode ser compreendido como práticas e valores implicitamente ensinados e aprendidos no interior das escolas, tão pouco discutido, deve ser imprescindivelmente pensado nas práticas educativas de qualquer educador/a. É uma questão crítica que deve estar presente na formação de docentes e no trabalho pessoal/profissional para que os professores e as professoras possam descontruir crenças e práticas naturalizadas e reconstruir um conhecimento crítico. Isso requer reconhecer e reprovar a cultura androcêntrica, respeitar as diversas perspectivas culturais (MONTANÉ LÓPEZ, 2015), e expressar idênticas expectativas de sucesso para alunos e alunas. 


\section{6 | VAMOS INVESTIR NOSSO TEMPO NESSE TEMA?}

Uma postura docente como a exemplificada neste artigo - "não costumo perder meu tempo com esse tema" - provavelmente tem implicações na prática pedagógica. Em sua prática o/a professor/a pode discriminar, ou não, meninos e meninas.

De acordo com Ribeiro e Pátaro (2015), alguns professores e professoras não consideram necessário abordar questões de sexismo e desigualdade de gênero na sala de aula, por acreditar que suas práticas de igualdade, liberdade e respeito com os meninos e as meninas dispensam a problematização dessas questões no exercício da docência. Provavelmente, foi essa tendência que prevaleceu no texto do atual PNE, que adotou um discurso genérico para excluir as discriminações específicas. Por sua vez, Carvalho (2012), ao enfatizar a omissão pedagógica de educadores e educadoras diante da manifestação de violência de gênero no cotidiano da escola, argumenta que quando eles e elas ignoram ou naturalizam essas manifestações, vistas muitas vezes como inocentes brincadeiras, entre seus colegas ou entre alunos e alunas no ambiente escolar, estão reproduzindo e reforçando a violência.

A escola, como uma instituição construtora de conhecimentos e identidades, através de suas educadoras e educadores, "tem um papel fundamental na desconstrução da violência simbólica e da cultura da inferiorização de gênero, de raça, de classe social e de geração", promovendo a transversalidade de gênero e outras questões no seu currículo (FALEIROS; FALEIROS, 2007, p. 33).

Assim, um docente que apresenta dificuldade em discutir a problemática de gênero, mostra a resistência de alguns homens e mulheres em não reconhecer e não visibilizar os espaços de poder onde as mulheres se manifestam em relação aos seus direitos públicos e privados (PINTO, 2010).

Quando educadores/as, de forma consciente ou não, deixam de abordar essas temáticas em seus discursos e práticas, quando se omitem no combate aos estereótipos de gênero e à violência simbólica, quando ignoram a gravidade das práticas sexistas existentes, corroboram com as violências simbólicas, dentre as quais a linguagem sexista e as baixas expectativas nas capacidades e competências científicas das meninas e mulheres são manifestações corriqueiras. Enfim, perdem a oportunidade de se envolver na construção de um mundo melhor, propiciada pela perspectiva crítica de gênero.

Inclusive e especialmente, se o docente conhecesse e se engajasse na problemática de gênero nas ciências, deveria estimular e atrair estudantes mulheres para a Física, inserindo a reflexão neste campo de conhecimento, onde são raras as que conseguem se incluir e permanecer na carreira (CARTAXO, 2012). 


\section{REFERÊNCIAS}

AGRELLO, D. A.; GARG, R. Mulheres na física: poder e preconceito nos países em desenvolvimento. Revista Brasileira Ensino Física, v. 31, n. 1, p. 1305.1-1305.6, 2009.

AMORIM, V. G. de; CARVALHO, M. E. P. de. Mapeamento realizado das produções acadêmicas sobre as mulheres em física. In: PEREIRA, M. Z. C.; ALBINO, C. A. A. (Org.). Série: ensaios sobre questões curriculares. João Pessoa: UFPB, 2015. p. 228-248.

AMORIM, V. G. de; PINTO, É. J. S.; CARVALHO, M. E. P. de. Sentidos e significados de gênero atribuídos por docentes da disciplina de física do ensino médio do IFPB. In: DIAS, A. F.; SANTOS, E. F.; CRUZ, M. H. S. (Org.). Gêneros, feminismos, poderes e políticas públicas: investigações contemporâneas. Campina Grande, PB: Realize, 2016. p. 3850-3862.

BANDEIRA, L. Três décadas de resistência feminista contra o sexismo e a violência feminina no Brasil: 1976 a 2006. Revista Sociedade e Estado, Brasilía, DF, v. 24, n. 2, p. 401-438, maio/ago. 2009.

BELTRÃO, K. I.; ALVES, J. E. D. A reversão do hiato de gênero na educação brasileira no século XX. Cadernos de Pesquisa, v. 39, n. 136, p.125-156, jan./abr. 2009. Disponível em: <http://www.scielo.br/pdf/cp/v39n136/ a0739136.pdf >. Acesso em: 10 dez. 2015.

BOURDIEU, P. A dominação masculina. 2. ed. Rio de Janeiro: Bertrand Brasil, 2002.

BRASIL. Plano Nacional de Educação 2014-2024: lei $n^{\circ}$ 13.005, de 25 de junho de 2014. Aprova o Plano Nacional de Educação (PNE) e dá outras providências. Brasília, DF: Câmara dos Deputados, 2014. Disponível em: <http://www.observatoriodopne.org.br/uploads/reference/file/439/documento-referencia.pdf >. Acesso em: 26 maio 2016.

Presidência da República. Secretaria Especial de Políticas para as Mulheres. Plano nacional de políticas para as mulheres. Brasília, DF: PR; SPM, 2004. 104 p. Disponível em: <http://www.spm.gov.br/assuntos/ pnpm/plano-nacional-politicas-mulheres.pdf $>$. Acesso em: 28 maio 2016.

Presidência da República. Secretaria Especial de Políticas para as Mulheres. II plano nacional de politicas para as mulheres. Brasília, DF: PR; SPM, 2008. 204 p. Disponível em: <http://bvsms.saude.gov.br/bvs/publicacoes/II_PNPM.pdf>. Acesso em: 28 maio 2016.
Presidência da República. Secretaria Especial de Políticas para as Mulheres. Plano nacional de politicas para as mulheres: 2013-2015. Brasília, DF: PR; SPM, 2013. 114 p. Disponível em: <http://www.spm.gov. br/assuntos/pnpm/publicacoes/pnpm-2013-2015-em22ago13.pdf>. Acesso em: 28 maio 2016.

BUARQUE, C. Roda viva. 1967. Disponível em: <https:// www.letras.mus.br/chico-buarque/45167/>. Acesso em: 3 jan. 2016.

BURGER, C. et al. Gender equity in science, engineering, and technology. In: KLEIN, S. S. et al. (Gen. Ed.). Handbook for achieving gender equity through education. 2. ed. New York; London: Routledge, 2010. p. 255279.

CARTAXO, S. M. C. Gênero e ciência: um estudo sobre as mulheres na física. 2012. 126 f. Dissertação (Mestrado em Política Científica e Tecnologia)- Universidade Estadual de Campinas, Campinas, 2012.

CARVALHO, M. E. P. de. Relações de gênero em cursos masculinos: engenharias mecânica e civil, física, matemática e ciência da computação. João Pessoa: Universidade Federal da Paraíba, 2014. Projeto de pesquisa financiado pela Chamada MCTI/CNPQ/MEC/ CAPES N²2/2014 - Ciências Humanas, Sociais e Sociais Aplicadas. Processo: 471892/2014-9.

Violências na escola: o que isso tem a ver com violências de gênero?. In: ANDRADE, Fernando (Org.). Escola: faces da violência, faces da paz. João Pessoa: Ed. Universitária da UFPB, 2012. p. 87-110.

CARVALHO, M. E. P. de; ANDRADE, F. C. B.; JUNQUEIRA, R. D. Gênero e diversidade sexual: um glossário. João Pessoa: Ed. Universitária da UFPB, 2009.

CARVALHO, M. E. P. de; RABAY, G. Gênero e educação superior: apontamentos sobre o tema. João Pessoa: Editora da UFPB, 2013.

CARVALHO, M. E. P. de; RABAY, G.; MORAIS, A. B. A. Pensar o currículo da educação superior da perspectiva da equidade e transversalidade de gênero e do empoderamento das mulheres: uma breve introdução. Espaço do Currículo, v. 6, n. 2, p. 317-327, maio/ago. 2013.

CONNELL, R. W.; MESSERSCHMIDT, J. W. Masculinidade hegemônica: repensando o conceito. Revista Estudos Feministas, v. 21, n. 1, p. 424, jan./abr. 2013. 
DANIELSSON, A. T. Exploring woman university physics students 'doing gender' and 'doing physics'. Gender and Education, v. 24, n. 1, p. 25- 39, Jan. 2012.

DÍAZ MARTÍNEZ, C. La perspectiva de género en la investigación social. In: FERRANDO, M. G. et al. (Comp.). El análisis de la realidad social: métodos y técnicas de investigación. 4. ed. Madrid: Alianza Editorial, 2015. p. 176-201.

FALEIROS, V. P.; FALEIROS, E. S. Escola que protege: enfrentando a violência contra crianças e adolescentes. Brasílía, DF: Organização das Nações Unidas para a Educação, a Ciência e a Cultura; Ministério da Educação, 2007.

FLICK, U. Introdução à pesquisa qualitativa. 3. ed. Porto Alegre: Artmed, 2009.

GILL, R. Análise de discursos. In: BAUER, M. W.; GASKELL, G. Pesquisa qualitativa com texto, imagem e som: um manual prático. Petrópolis: Vozes, 2014. p. 244-270.

HARAWAY, D. J. Modest witness@second millenium: female meets oncomouse: feminism and technoscience. New York: Routledge, 1998.

HOOKS, B. Feminism is for everybody: passionate politics. Cambridge, MA: South End Press, 2000.

KELLER, E. F. Qual o impacto do feminismo na ciência? Cadernos Pagu, Campinas, n. 27, p.13-34, jul./dez. 2006.

LESSA, P. A fabricação dos tecno-bio-corpos e a produção do sexismo na linguagem. Niterói, RJ: Universidade Federal Fluminense, 2001. Relatório final de pós-doutorado.

LIMA, B. S. O labirinto de cristal: as trajetórias das cientistas na física. Revista Estudos Feministas, Florianópolis, v. 21, p. 883-903, set./dez. 2013.

Teto de vidro ou labirinto de cristal?: as margens femininas das ciências. 2008. Dissertação (Mestrado em História) - Universidade de Brasília, Brasília, DF, 2008.

LIMA JÚNIOR , P. R. M. Diferenças e semelhanças entre graduandos em física com respeito ao gênero: uma análise das interações discursivas sob a perspectiva sociocultural. 2009. Dissertação (Mestrado Acadêmico em Ensino de Física) - Universidade Federal do Rio Grande do Sul, Porto Alegre, 2009.
LOMBARDI, M. R. Engenheira e gerente: desafios enfrentados por mulheres em posições de comando na área tecnológica. In: COSTA, A. O. et al. (Org.). Mercado de trabalho e gênero: comparações internacionais. Rio de Janeiro: FGV, 2008. p. 387-402.

MELTZOFF, A. N. Estereótipo de que 'matemática é para garotos' afasta meninas da tecnologia, diz pesquisador. BBC Brasil, São Paulo, 13. set. 2015. Entrevista concedida a Camila Costa. Disponível em: <http://www. bbc.com/portuguese/noticias/2015/09/150831_entrevista_andrew_meltzoff_cc>.Acesso em: 12 maio 2016 .

MONTANÉ LÓPEZ, A. Tranversalidad de gênero: educación, formación y empleabilidad. Revista Espaço do Currículo, João Pessoa, v. 8, n. 2, p. 176-194, maio/ago. 2015.

MORENO, M. Como se ensina a ser menina: o sexismo na escola. São Paulo: Moderna, 1999.

OLIVEIRA, D. G.; OLIVEIRA, D. Desconstruindo práticas sexistas no ambiente escolar. Curitiba: Governo do Paraná/Secretaria de Educação, 2012.

ONU MULHERES Brasil. Visão geral. [2016]. Disponível em:<http://www.onumulheres.org.br/brasil/visao-geral/>. Acesso em: 10 dez. 2015.

PINTO, C. R. J. Dossiê: feminismo, história e poder. Revista de Sociologia e Política, Curitiba, v. 18, n. 36, p. 15-23, jun. 2010.

PINTO, É. J. S.; AMORIM, V. G. de; CARVALHO, M. E. P. de. Entre discriminação explícita e velada: experiências de alunas de física na educação superior. Revista Diversidade e Educação, v. 4, n. 8, p. 13-32, jul./dez. 2016. Disponível em: <https://www.seer.furg.br/divedu/ article/view/6737>. Acesso em: 08 mar. 2017.

PROGRAMA DAS NAÇÕES UNIDAS PARA O DESENVOLVIMENTO. Relatório do desenvolvimento humano 2015. O trabalho como motor do desenvolvimento humano. New York: PNUD, 2015. Disponível em: <http:// www.br.undp.org/content/brazil/pt/home/library/relatorios-de-desenvolvimento-humano/relatorio-do-desenvolvimento-humano-200014/>. Acesso em: $10 \mathrm{dez} .2015$.

Relatório do desenvolvimento humano 2014. Sustentar o progresso humano: reduzir as vulnerabilidades e reforçar a resiliência. New York: PNUD, 2014. Disponível em: <http://www.br.undp.org/content/brazil/ pt/home/library/relatorios-de-desenvolvimento-humano/relatorio-do-desenvolvimento-humano-200013/>. Acesso em: 10 dez. 2015. 
RIBEIRO, A. S.; PÁTARO, R. F. Reflexões sobre o sexismo a partir do cotidiano escolar. Revista Educação e Linguagem, Campo Mourão, v. 4, n. 6, jan./jun. 2015.

RIO GRANDE DO SUL. Secretaria de Política para as Mulheres. Manual para o uso não sexista da linguagem: o que bem se diz bem se entende. Porto Alegre: Secretaria de Comunicação e Inclusão Digital, 2014.

ROSEMBERG, F. Educação formal, mulher e gênero no Brasil contemporâneo. Revista Estudos Feministas, ano 9, p. 515-540, 2001. Disponível em: <http://www.scielo. br/pdf/ref/v9n2/8638.pdf>. Acesso em: 10 dez. 2015.

ROSEMBERG, F.; MOURA, N. C.; SILVA, P. V. B. Combate ao sexismo em livros didáticos: construção da agenda e sua crítica. Cadernos de Pesquisa, São Luís, v. 39 , n. 137 , p. $489-519$, maio/ago. 2009.

SABINO, M. J. C.; LIMA, P. V. P. S. Igualdade de gênero no exercício do poder. Estudos Feministas, Florianópolis, v. 23, n. 3, p. 406, set./dez. 2015.

SCHIEBINGER, L. O feminismo mudou a ciência? Bauru: EDUSC, 2001.

SCOTT, J. Gender and politics of history. New York: Columbia University Press, 1988.

SILVA, M. N. A Educação da mulher e da criança no Brasil Colônia. In: STEPHANOU, M.; BASTOS, M. H. C. (Org.). Histórias e memórias da educação no Brasil: séculos XVI-XVIII. 4. ed. Petrópolis: Vozes, 2010. v. I. p. 131-139.
SILVA, T. T. (Org.). Identidade e diferença: a perspectiva dos estudos culturais. Petrópolis: Vozes, 2000.

TABAK, F. O laboratório de Pandora: estudos sobre a ciência no feminino. Rio de Janeiro: Garamond, 2002.

TEIXEIRA, A. B. M.; FREITAS, M. de A. Mulheres na docência do ensino superior em cursos de física. Ensino Em Re-Vista, Uberlândia, MG, v. 21, n. 2, p. 329-340, jul./dez. 2014.

UNESCO. Conferência Mundial sobre Educação Superior. Declaração mundial sobre educação superior no século XXI: visão e ação. Paris: UNESCO, 1998. Disponível em: <http://www.direitoshumanos.usp. br/index.php/Direito-a-Educa\%C3\%A7\%C3\%A3o/ declaracao-mundial-sobre-educacao-superior-no-seculo-xxi-visao-e-acao.html>. Acesso em: 10 dez. 2015.

VELHO, L.; LEÓN, E. A construção social da produção científica por mulheres. Cadernos Pagu, v. 10, p. 309344, 1998.

WAISELFISZ, J. J. Juventude viva: mortes matadas por armas de fogo: mapa da violência 2015. Brasília, DF: Secretaria-Geral da Presidência da República; Secretaria Nacional de Juventude; Secretaria de Políticas de Promoção da Igualdade Racial, 2015a. 112 p.

Mapa da violência 2015: homicídio de muTheres no Brasil. Brasília, DF: ONU Mulheres; OPAS/ OMS; SPM; Flacso, 2015b. 83 p. 